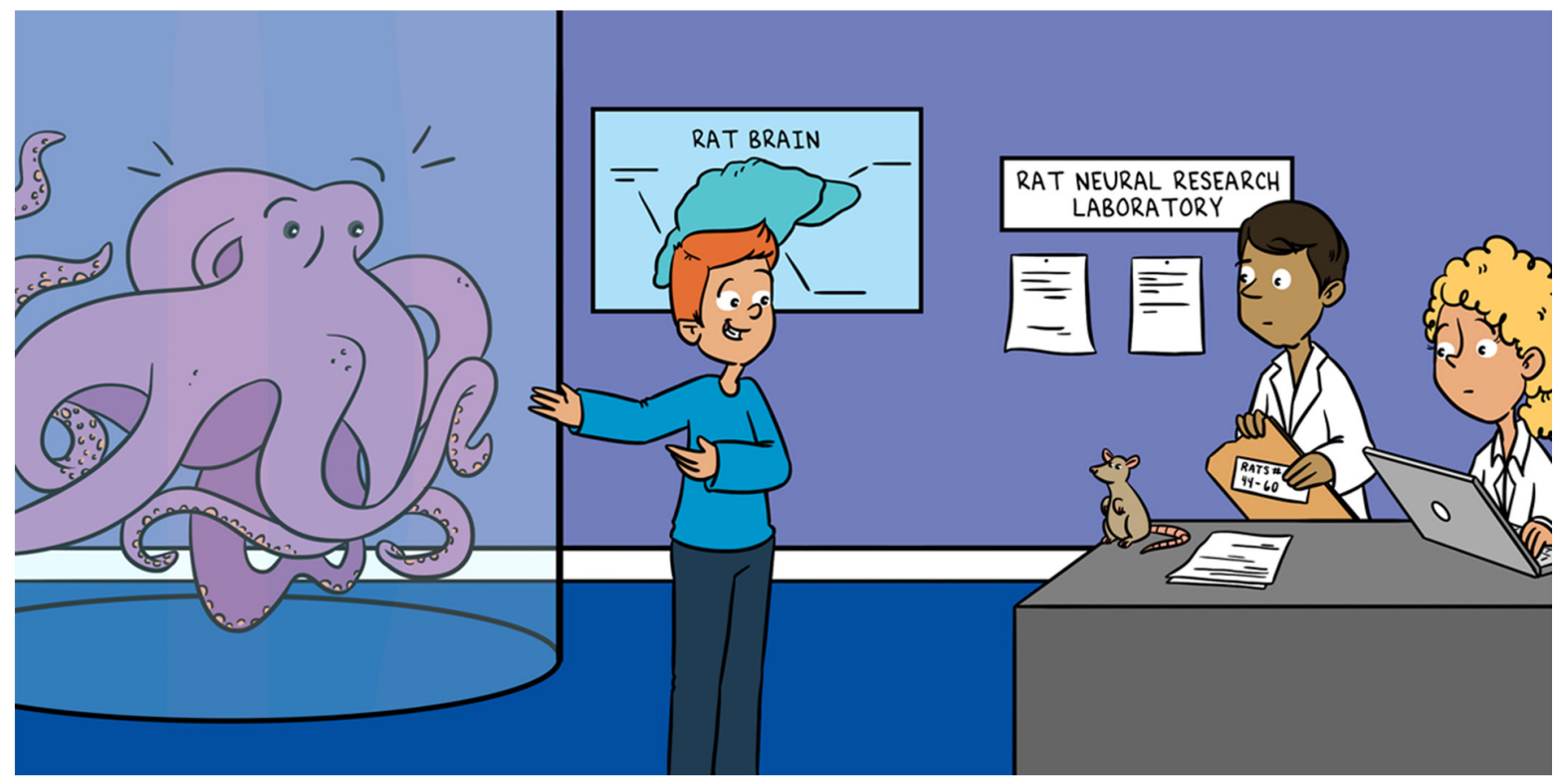

\title{
THE OCTOPUS: A UNIQUE ANIMAL FOR STUDYING THE BRAIN
}

\section{Tal Shomrat ${ }^{*}$ and Nir Nesher}

Faculty of Marine Sciences, Ruppin Academic Center, Michmoret, Israel

\section{YOUNG REVIEWERS:}

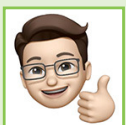

AVIV

AGE: 15

ISRAEL

舅会
ARTS AND SCIENCE ACADEMY AGES: $14-15$
What are the structures and functions of the brain that are important for complex learning, such as the ability to quickly figure out how to activate a new application in your smartphone? What are the brain mechanisms that allow memories, like the name of your first-grade teacher, to be stored and quickly recalled, even many years later? Which part of the brain generates the creativity and flexibility of thought necessary for learning a new smartphone interface, for example? These questions are some of the most studied in neuroscience, which is the science that studies the brain and nervous system. In this article, we will tell you how research on the octopus's brain could help us find answers to these questions. By comparing the structure and function of the octopus brain to the brains of other animals, we might even obtain clues about the workings of the human brain. 
Figure 1

The body structure of the octopus. The octopus has 8 arms, each with hundreds of suckers that can stick to prey or rocks. Suckers are similar to our tongues, and they allow the octopus to experience taste and texture. The arms are directly connected to the octopus's head. The head is also connected to the body, which contains all the internal organs such as the gills, the digestive system, and the reproductive system. The siphon is an interesting organ, used to "exhale" water from the gills, to secrete feces, and to spray ink and water for protection and hunting (Photo credit: Benny Hochner, HUJI).

\section{VIDEO 1}

Octopus vulgaris solves a novel problem. It opens screwed lid of a bottle to gain a piece of fish.

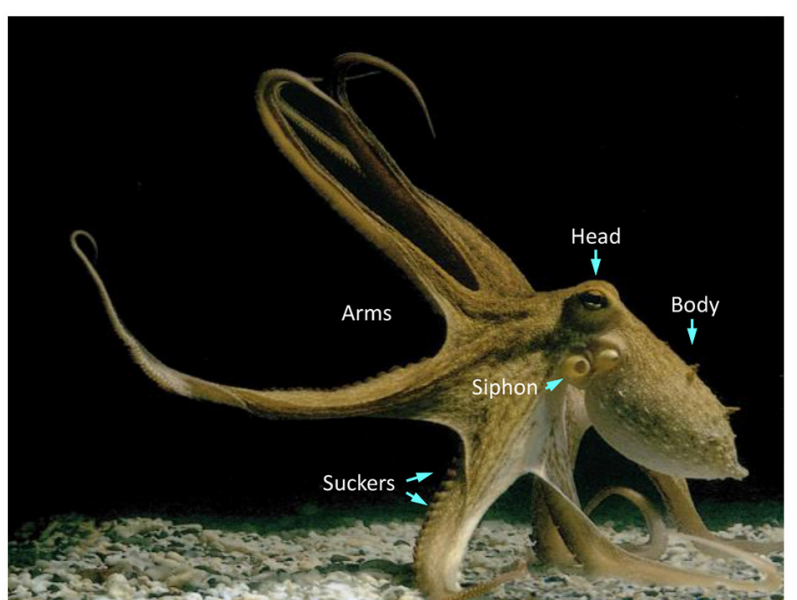

Figure 1

\section{WHY IS THE OCTOPUS SPECIAL?}

Octopi, cuttlefish, squids, snails, and clams all belong to the class of animals called mollusks. Octopi, cuttlefish, and squids are in a group within the mollusks called cephalopods. Cephalopod means "head-foot" in Greek, since the heads of these animals are directly connected to their "legs" (Figure 1). In contrast to snails and clams, cephalopods have an exceptionally developed central brain which allows cephalopods to exhibit complex behaviors that are equal to those of mammals and birds [1]. Simple mollusks, like the snail, exhibit only very simple behaviors. For example, a hungry sea snail will move toward the scent of its favorite algae. It is possible for a snail to learn that a certain smell comes from a particularly delicious food, and it will then choose this smell over other smells in the future. But, in general, snails will always repeat these same simple behaviors to find food.

In contrast to the snail, the octopus exhibits much more complex behavior. The octopus eats clams, crabs, and fish. Each of these prey types requires a different hunting behavior: for example, clams must be removed from their shells, and this is not an easy task! The octopus drills a hole in the shell and injects venom to paralyze and relax the clam's muscles, so it can be pulled out. To hunt crabs, the octopus carefully sneaks up on a crab, so that it does not run away, and then the octopus attacks quickly and with great skill, so as not to get pinched by the crab. The octopus not only learns and remembers how to hunt different types of prey, but it probably also remembers the details of when and where it is best to hunt each prey type.

Another example of complex behavior is that octopi can learn from observing other octopi. For example, from watching another octopus open a jar of food by unscrewing the lid, the observing octopus also learns to do so (Video 1) opening the jar much faster than another octopus that had to learn to open the jar without observing it being 


\section{VIDEO 2}

Octopus vulgaris plays with a bottle cap.

\section{MODEL ANIMAL}

Lab animal, as opposed to wild animals (field research) or farm animals, which has certain features allowing for research whose results create general understanding of animals' biology.

\section{COMPARATIVE BIOLOGY}

The study of differences between organisms, to understand life patterns and the roles of organisms in an ecosystems. opened. Octopi are also extremely curiosity and even playful (Video 2). These examples clearly show that octopi are not simple snails!

\section{WHAT MAKES THE OCTOPUS A PROPER MODEL ANIMAL IN NEUROSCIENCE?}

The main model animals that scientists use to study the brain are rats and mice. Compared with octopi, rats and mice are much easier to grow and breed in the lab! Also, to help answer research questions, scientists can manipulate the genes of mice and rats. These gene manipulations are not yet possible in octopi. The most significant difference is that rats and mice are mammals, like humans, and therefore share the most similarity with us when it comes to brain structure and function. So, why study octopi to understand the brain?

Well, what makes the octopus a good model animal is not the similarity, but the difference! Mammals such as rats and humans shared an ancestor with octopi more than half a billion years ago (Figure 2). This prehistoric ancestor was a kind of brainless worm that developed along two separate pathways-one that led to the development of mammals, and another that led to the development of the octopus. Since the octopus developed in such a different way, we can compare the brain structure and function of the octopus with that of other animals, such as rats and mice, and through the differences and similarities we can learn some important things about the brain [1].

Imagine that you are a visitor from the past, you have never seen a smartphone, and you want to understand how it works. One way to do this would be to compare two types of smartphones, for example Apple's iPhone and Samsung's Galaxy. By examining both devices you would find, for example, that both have touch screens, an interface based on graphical icons, and a continuous connection to the internet. Since these characteristics are shared, you could conclude that they are necessary parts of the smartphone. In contrast, you might notice that the operating systems, charging cables, and icons are different. You could conclude that these are not critical characteristics, and that the same functions can be achieved in different ways. Similarly, comparing the brain structure and function of the octopus with that of the rat, we can uncover basic biological principles, such as which brain structures are needed for complex behavior and high-level learning. We can also examine the mechanisms that developed in the octopus's brain but are not present in simple snails, and assume that these "new" mechanisms give the octopus abilities like those of rats and mice. This comparison style of animal research is called comparative biology [1]. 
Figure 2

Octopi and mammals both evolved from a worm with a simple nervous system that lived more than half a billion years ago. The brains of mammals and octopi developed completely separately. The octopus brain resembles the brain of an insect, while the rat brain is similar to the human brain. The octopus hippocampus, in the upper part of the brain, is used for sight-based learning and is called the vertical lobe (green). The bodily nervous system of the octopus (PNS, yellow) is highly developed. A rat brain is shown on the left, for comparison [Image credit: Michael Appleboim (octopus), Anat Shomrat (worm and rat)].

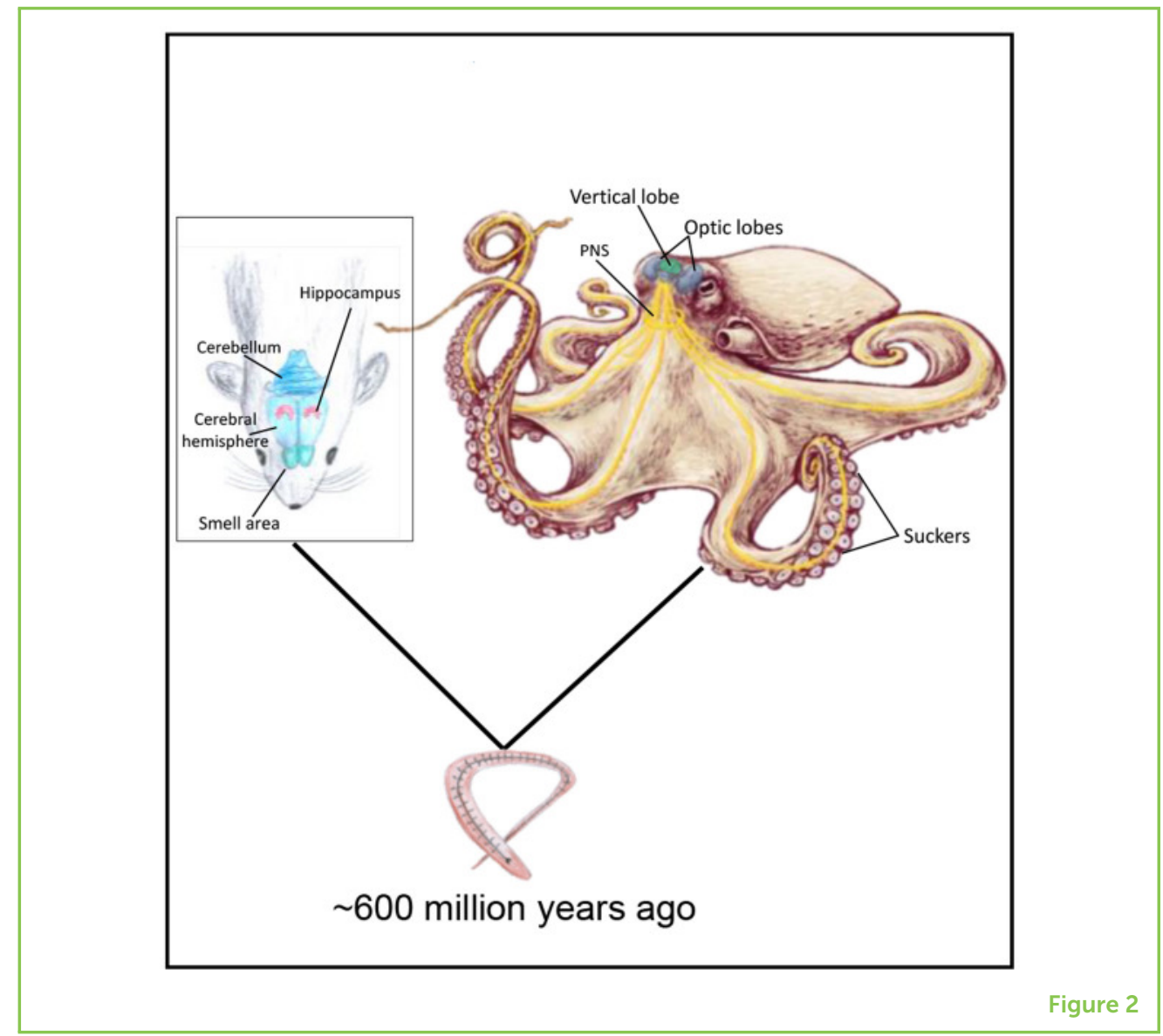

\section{INTERESTING FINDINGS FROM OCTOPUS RESEARCH}

In simple mollusks like snails that do not have a central brain, learning and memory occur in neural centers that are spread throughout the body. For example, when a snail eats a food that burns its mouth, the memory is created and saved by the nervous system controlling the mouth, and the snail will draw back from that food the next time it tastes it. In contrast, in mammals like humans, the learning and memory occur in the brain and not the body organs' nervous system. For example, the memory of the taste of vanilla when you see a white ice cream cone occurs in the brain, not the tongue or eyes' nervous. Mammalian brains also have an area called the hippocampus, which puts together the details of things we see, hear, smell, and feel, to form a memory of a certain event. Inside the octopus's brain, there is an area similar to the hippocampus called the vertical lobe (Figure 2).

The arrangement of nerve cells in the hippocampi of mammals and octopi both developed in the pattern of a crisscross net, which is probably crucial for making the many connections needed to form a memory. Since both mammals and octopi developed a specific brain area for creating memories, we can conclude that such a brain structure with its crisscross neural network arrangement, is necessary for complex learning, just as different smartphones have 
similar components, like a touch screen. The nerve cells in the hippocampus can change their connections quickly and efficiently to create new memories, for example, by connecting nerve cells related to a certain song with another group of nerve cells representing the face of the singer. The nerve cells in the octopus's vertical lobe can change the strength of their connection quickly and efficiently, but the mechanism by which these changes occur is different from the mechanism found in mammals. From this finding, we conclude that the ability to change connections in the hippocampus is crucial for learning, but connections can change in different ways in different animals $[2,3]$.

Another interesting and unique characteristic of the octopus is the development of two hippocampus like areas-one to create memories based on sight and another to create memories related to taste and touch. We conducted a study in our lab in which we found that a brain chemical called serotonin strengthens connections in the vertical lobe, the octopus "hippocampus" responsible for creating memories based on what the octopus sees but, in the second hippocampus like brain structure, which creates memories based on touch and taste, serotonin weakens the connections. Now we would like to understand if the different effects of serotonin in these two areas is related to their different functions.

Another significant difference between octopi and mammals is the presence of an extremely well-developed bodily nervous system in the octopus (Figure 2). Unlike our hands, the octopus's arms can perform a variety of actions independently, without dependence on the brain. For example, if we disconnect an octopus's arm from its body and pinch its edge, the arm will quickly pull away. In contrast, if a human hand were somehow disconnected from the body and touched something hot, it would stay motionless. The complexity of the octopus's bodily nervous system suggests that, similar to simpler mollusks like snails, memory from simple learning might form inside the hand itself, so that the hand will behave differently after learning, even if it is disconnected from the brain!

\section{SUMMARY}

Rats are currently the main animal used to study the brain, because they are easy to house and breed in the lab and scientists can manipulate their genes. However, the octopus has behavioral abilities similar to those of mammals like rats, but the octopus has a very different brain, which developed along a unique route over the course of evolution. These unique characteristics make the octopus a good model animal for comparative biology research. Comparing the brains of octopi and mammals can help us understand the importance and function of various brains structures and mechanisms, while also 
teaching us interesting things about the unique and fascinating brain of the octopus [1].

\section{REFERENCES}

1. Schnell, A. K., Amodio, P., Boeckle, M. and Clayton, N. S. 2021. How intelligent is a cephalopod? Lessons from comparative cognition. Biol Rev. 96:162-78. doi: 10.1111/brv.12651

2. Shomrat, T., Turchetti-Maia, A. L., Stern-Mentch, N., Basil, J. A., and Hochner, B. 2015. The vertical lobe of cephalopods: an attractive brain structure for understanding the evolution of advanced learning and memory systems. $J$. Comp. Physiol. A Neuroethol. Sens. Neural Behav. Physiol. 201:947-56. doi: 10.1007/s00359-015-1023-6

3. Shomrat, T., Graindorge, N., Bellanger, C., Fiorito, G., Loewenstein, Y., and Hochner, B. 2011. Alternative sites of synaptic plasticity in two homologous "fan-out fan-in" learning and memory networks. Curr. Biol. 21:1773-82. doi: 10.1016/j.cub.2011.09.011

SUBMITTED: 03 August 2021; ACCEPTED: 28 October 2021; PUBLISHED ONLINE: 23 November 2021.

EDITED BY: Idan Segev, Hebrew University of Jerusalem, Israel

CITATION: Shomrat T and Nesher N (2021) The Octopus: A Unique Animal for Studying the Brain. Front. Young Minds 9:752743. doi: 10.3389/frym.2021.752743

CONFLICT OF INTEREST: The authors declare that the research was conducted in the absence of any commercial or financial relationships that could be construed as a potential conflict of interest.

COPYRIGHT @ 2021 Shomrat and Nesher. This is an open-access article distributed under the terms of the Creative Commons Attribution License (CC BY). The use, distribution or reproduction in other forums is permitted, provided the original author(s) and the copyright owner(s) are credited and that the original publication in this journal is cited, in accordance with accepted academic practice. No use, distribution or reproduction is permitted which does not comply with these terms.

\section{YOUNG REVIEWERS}

\section{AVIV, AGE: 15}

My name is Aviv, I like to do many things: playing the piano-I have traveled to international competitions, and taking part in debates-speaking in front of an audience on various topics. I also like to play basketball, travel, and play ping pong. 


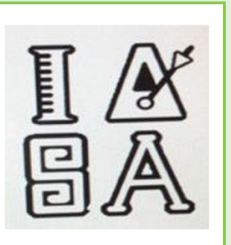

ISRAEL ARTS AND SCIENCE ACADEMY, AGES: 14-15

Israel Arts and Science Academy is a place for curious students who like to learn. In the 9th grade, as part of the elective classes we are the students who read scientific papers we chose. The course was lead by Anat Maoz, the principle of our secondary school, which has a Master's degree in marine biology.

\section{AUTHORS}

\section{TAL SHOMRAT}

I am a researcher at the Faculty of Marine Sciences at Ruppin Academic Center. In a lab on the coast of the Mediterranean Sea, I grow octopi, cuttlefish, and flat worms called planarians. Using behavioral tests and observing the brain activity of these three animals, I try to understand the basis of complex behavior, learning, and memory. I have been diving since a very young age, and I became acquainted with the octopus in my childhood, much before I knew that one day I would be a scientist, studying these wondrous creatures. *tal.shomrat@mail.huji.ac.il

\section{NIR NESHER}

I was raised in Kibbutz Beit Zera. When I was younger, I spent most of my time in nature and doing agricultural work. After the army, I traveled the world for almost 10 years, and it sparked my strong interest in topics related to marine sciences and the Earth. When I came back, I studied marine sciences. Now I have a Ph.D. in that field and I am a senior lecturer at the Faculty of Marine Sciences at the Rupin Academic Center. In our lab, Dr. Shomrat and I study the octopus, one of the most interesting animals in nature. We focus on behavior, memory, learning and the unique motor control system that developed in this flexible, multi-armed creature. 